\title{
PREPAREDNESS AND ATTITUDINAL DISPOSITION TOWARDS MENARCHE AMONG IN-SCHOOL GIRLS IN IKENNE
}

\section{Fadipe Omotolani Abiodun and Oyerinde O. O. (Ph.D)}

Department of Public Health and Allied Health, Babcock University, Ilishan-Remo

Cite this article:

Fadipe O.A., Oyerinde O. O. (2021), Preparedness and Attitudinal Disposition Towards Menarche Among InSchool Girls in Ikenne. African Journal of Health, Nursing and Midwifery 4(4), 31-51. DOI: 10.52589/AJHNMTKWZU2D9.

\section{Manuscript History}

Received: 6 June 2021

Accepted: 5 July 2021

Published: 12 July 2021

Copyright $\odot 2020$ The Author(s). This is an Open Access article distributed under the terms of Creative Commons AttributionNonCommercial-NoDerivatives 4.0 International (CC BY-NC-ND 4.0), which permits anyone to share, use, reproduce and redistribute in any medium, provided the original author and source are credited.
ABSTRACT: The study examines the knowledge and attitudinal disposition towards menarche among in-school girls. The study utilised a cross-sectional descriptive design using quantitative (questionnaire). A multi-stage sampling technique was employed for the selection of 422 in-school girls in the selected secondary schools while a purposive sampling technique was used to select 13 school girls for focus group discussion. Frequency distribution table and summaries of descriptive statistics, inferential statistics of Pearson productmoment correlation analysis were used to test the research hypothesis. The study found that Most of the students $40.5 \%$ of the in-school girls have a high level of preparedness for menarche. Majority of the in-school girls $34.4 \%$ had moderate levels of attitudinal disposition towards menarche. Majority of the in-school girls $45 \%$ had a good level of coping mechanism towards menarche among in-school girls. There was a significant relationship between the level of preparedness for menarche and the attitudinal disposition of in-school girls in Ikenne Local Government. There was a significant relationship between the level of preparedness for menarche and the coping mechanism of in-school girls in Ikenne Local Government. The calculated $R$ Squared and p-value for preparedness for menarche and attitudinal disposition is 0.716 which signifies $71.6 \%$ contribution to coping with menarche among in-school girls in Ikenne Local Government Area. The study recommends that there is a need for teachers to build a peaceful and healthy transition into womanhood through adequate preparation and provision of resources for young girls. Parents should create more time for their female adolescents towards given necessary psychosocial support as they enter menarche.

KEYWORDS: Preparedness and Attitudinal Disposition Towards Menarche Among In-School Girls in Ikenne 


\section{INTRODUCTION/BACKGROUND}

The cyclical occurrence of menarche has generated different myths and superstitions in various cultures over the ages in Nigeria. A girl's culture, reference group, educational status and religious inclination largely influence her psychosocial dimensions into menarche among adolescents. A woman's positive disposition to menstruation often derives from premenarcheal preparation, education and positive early menstrual experiences (Adebimpe, 2017).

One of the major challenges before every adolescent girl is to handle menarche, which is a normal body function in females. Menarche is an important reproductive health function, yet it has been dealt with secrecy in India (United Nations Children's Fund, 2018). Several taboos and social and cultural restrictions still exist concerning menarche (Jegede, 2019; Awolude, 2018; Singh, 2016), which intimidate the girls and make their life difficult. Therefore, menarche is generally unwelcome by adolescent girls in Nigeria. Also, a significant body of evidence from high-income countries indicates that early menarche, typically described as menarche before age 12, increases the vulnerability of adolescent girls to adverse sexual and reproductive health outcomes, including early pregnancy and childbearing, STIs, early sexual initiation, and sexual violence (Deardorff, 2017).

Furthermore, in developing countries psychosocial implication of menarche is huge on adolescent girls as they are often denied access to water and sanitation when they need it most (Kamath, Ghosh, Lena \& Chandrasekaran 2016). The overall perception in Nigeria is that menstrual fluid is dirty and polluting, and this explains the secrecy within which its management shrouded (Ibaishwa \& Achakpa, 2016). Consequently, inadequate menarche remains a major problem for girls and women in resource-poor countries (Kuhlmann, Henry, $\&$ Wall, 2017). Poor menarche care is a major source of worry, humiliation, monthly absenteeism, and poor academic performance for many schoolgirls (Patle \& Kubde, 2019). Also, a culture of silence surrounds menarche, and inadequate health facilities and hygiene materials predispose adolescents to psychosocial trauma and cyclic absenteeism from school (Aluko, 2018). In Nigeria, mothers who have information about reproductive health and menarche often withhold such information to prevent their girls from becoming "promiscuous" (Forward, 2016). Similarly, misconceptions about the physiological processes and characteristics of menarche are evident among girls preparing for menarche (Shakweer, 2016). In South-West Nigeria, some girls, especially those from low socioeconomic backgrounds, considered sexual activity to be their means of socioeconomic survival (Ajah, 2015). Thus, girls' conceptions of menarche are distorted and conflated with sexuality (Tracy, Grover, \& Macgibbon, 2016).

Lack of knowledge of menarche has resulted in several psychosocial experiences for inschool girls like emotions at menarche, including shame, guilt, fear and anxiety, and these emotions could continue to be associated with menstruation throughout a woman's reproductive years (Shanbhag, 2016; Tiwari, 2016). Therefore, the less accurate knowledge girls have about what menstruation entails and the less prepared a girl is to start menstruating, the more secretive and negative they may feel toward the menstrual experience (Marván \& Molina-Abolnik, 2016). Self-perception is the second psychological factor that could contribute to beliefs and attitudes towards menstruation. 
In some cultures, in the Yoruba ethnic group, menarche period has been regarded as a period of bad luck, that women should not wash their hair and eat raw or cold food during menstruation, and that it is easier to get sick during or after menstruation (Ademikanra, 2016). Notwithstanding that most cultures in Nigeria have undergone varying degrees of social changes, there are shreds of evidence that women may still adopt these cultural stereotypes and misconceptions about menarche at a young age (Chrisler, 2016; Koff \& Rierdan, 2015; Ademikanra, 2016; Ajao, 2019). Menarche has several misconceptions and stigma often bring about shame, guilt, and feelings of being unclean concerning menstruation and, as a result, may lead to teenage girls' negative expectations of menarche. A menarche is a pivotal event for organizing teenage girls' self-image and sexual identification (Golub, 2016; Koff, Rierdan, \& Silverstone, 2018).

People's subjective perceptions of physical characteristics, such as physical appearance, are one of the means for understanding self-image (Blyth, Simmons, \& Zakin, 2015). Omigbodun, Bella-Awusah \& Adeniyi, (2018) reported increased incidence of mood disorder, low-self-esteem and other mental health morbidities among adolescent girls in Junior secondary schools in the Ibadan metropolis as a result of entering into menarche stage and the feeling of shame and disgrace as perpetrated by their colleagues and close family relations. It was emphasized that there is need for a premenarcheal teenage girls' dissatisfaction with their bodies may result in confusion and a sense of inadequacy, which may, in turn, relate to negative expectations about the first onset of menstruation (Bartky, 2017) Early age at menarche is also associated with a high risk of aberrant behaviour, early sexual initiation, sexually transmitted infections including HIV, unintended pregnancy, and complications resulting from early childbirth, dropout from school and smoking in adolescence (Walvoord, 2011; Singh, Darroch, \& Ashford, 2014).

Social factors such as religion, culture, education, and socio-economic status have all been found to impact the attitudes and beliefs surrounding the experience of menstruation in some way or another (Çevirme, 2016; Cooper \& Koch, 2017; Johnston-Robledo \& Chrisler, 2017; Kumar \& Kundan, 2016; Marván \& Trujillo, 2017; Orringer \& Gahagan, 2016; Tiwari et al., 2016; Umeora \& Egwuatu, 2018; White, 2017; Wister, Stubbs \& Shipman, 2016; Wong \& Khoo, 2017). Given the paucity of studies relating to the psychosocial factors, it is therefore important to examine the study of knowledge and attitudinal disposition towards menarche among in-school girls.

\section{Research Questions}

1. What is the level of preparedness for menarche among in-school girls in Ikenne Local Government Area?

2. What is the menstrual attitudinal disposition of in-school girls in Ikenne Local Government Area?

3. What is the predictor of preparedness for menarche and attitudinal disposition on the coping mechanism of in-school girls in Ikenne Local Government

\section{Research Objectives}

The overall objective of the study is to examine the knowledge and attitudinal disposition towards menarche among in-school girls. 
1. To examine the level of preparedness for menarche among in-school girls in Ikenne Local Government Area?

2. To ascertain the level of menstrual attitudinal disposition of in-school girls in Ikenne Local Government Area?

3. To examine the predictor of preparedness for menarche and attitudinal disposition on coping mechanism of in-school girls in Ikenne Local Government

\section{METHODS AND DESIGN}

\section{Research Design}

This research utilized a cross-sectional descriptive design with the adoption of both quantitative research methods. The study considered the quantitative method involved the use of an interviewer-administered questionnaire.

\section{Population}

The study was carried out in five public secondary schools in Ikenne Local Government Area, one of the twenty Local Governments in Ogun State. Ikenne LGA has a total of 37 secondary schools. Of these secondary schools, eighteen are public or government-owned while the remaining nineteen (19) are private schools. This study focused only on students of public secondary schools. The public schools in the LGA are listed in the table below.

Table 1 showing the distribution of secondary schools in Ikenne LGA

\begin{tabular}{ll}
\hline SCHOOL & POPULATION \\
\hline Ajagbe High School, Iperu & 1186 \\
Akesan Community Grammar School & 760 \\
Irolu Community High School & 379 \\
Ogere Community High School & 318 \\
Christ Apostolic Grammar School, Iperu (Junior). & 1141 \\
Christ Apostolic Grammar School, Iperu (Senior). & 888 \\
Ilishan High School (Junior) & 800 \\
Ilishan High School (Senior) & 410 \\
Mayflower School (Junior) & 2530 \\
Mayflower School (Senior) & 2681 \\
United High School, Ikenne (Junior) & 420 \\
&
\end{tabular}


African Journal of Health, Nursing and Midwifery

ISSN: 2689-9418

Volume 4, Issue 4, 2021 (pp. 31-51)

www.abjournals.org

United High School, Ikenne (Senior) 359

Ikenne Community High School, Ikenne (Junior) 660

Ikenne Community High School, Ikenne (Senior) 467

Isanbi Comprehensive High School (Junior) 406

Isanbi Comprehensive High School (Senior) $\quad 400$

Ositelu Memorial College, Ogere (Junior). 639

Ositelu Memorial College, Ogere (Senior) 394

$\begin{array}{lr}\text { TOTAL } & 14,838\end{array}$

\section{Inclusion Criteria}

The girls who will be recruited for the study will be selected from the selected schools and the inclusion criteria include:

1. Girls must be registered students in the selected schools.

2. The girls must have started their menstruation.

\section{Exclusion Criteria}

The exclusion criteria for participants in this study were as follows:

1. This study will exclude girls who will not give their consent to participate in the study.

2. Girls that have not yet attained menarche

\section{Sample Size Determination and Sampling Technique}

The sample size used was obtained from the target population of junior secondary female students of the selected Junior Secondary School in Ikenne Local Government, Ogun State. The total population of the female students in junior secondary school classes from the five schools is 1,059 .

Sample size was determined using Leslie Kish's formula for computation of sample size (1963). 
Where; $\mathrm{Za} / \mathrm{b}=\mathrm{Z}$-scores corresponding to $\mathrm{a}$ one sided test $=1.96$

$\mathrm{d}^{2}=$ acceptable margin of error at $5 \%$ (standard value of $0.05 \%$ )

$\mathrm{p}=$ estimated prevalence $(50 \%)$

$\mathrm{q}=\quad 1-\mathrm{p}$

$\mathrm{N}=\left(\underline{1.96)^{2} \times 0.5(1-0.5)}=384.16\right.$

$0.05^{2}$

$10 \%$ of calculated sample size will be added to accommodate for non-response by participants.

$\mathbf{n}=384+10 \%$ (non-response bias)

$\mathbf{n}=384+38$

$\mathbf{n}=422$. The sample size for this study will therefore be 422 respondents

The sampling technique to be used in this study is random sampling technique; hat method.

STAGE 1: A public junior secondary school was chosen from each of the five towns that make up Ikenne LGA through the hat method. The schools are Isanbi Comprehensive High school (Ilisan), Ajagbe Community Grammar School (Iperu), Ogere Community High School (Ogere), Ikenne Community High School (Ikenne), Irolu Community High School (Irolu).

Table 2 Population of junior secondary school students in selected schools for the study

\begin{tabular}{|l|l|l|l|l|}
\hline Serial Number & Town & School & $\begin{array}{l}\text { Population } \\
\text { (Female) }\end{array}$ & $\begin{array}{l}\text { Population } \\
\text { (Male) }\end{array}$ \\
\hline 1 & Iperu & Ajagbe Community Grammar school & 256 & 265 \\
\hline 2 & Ogere & Ogere Community Grammar School & 100 & 109 \\
\hline 3 & Ikenne & Ikenne Community High School & 405 & 400 \\
\hline 4 & Ilisan & Isanbi Comprehensive High School & 178 & 175 \\
\hline 5 & Irolu & Irolu Community High School & 120 & 118 \\
\hline Total & & & $\mathbf{1 0 5 9}$ & $\mathbf{1 0 6 7}$ \\
\hline
\end{tabular}


STAGE 2: All classes from JSS1 to JSS3 were used for this study. The total number of female students in the school was retrieved from the vice principal (academics) office. The proportion for selection was calculated using the number of students in the school and the estimated sample size.

STAGE 3: After the proportion selection for each class, the number of participants from each class was selected randomly using the hat method, where serial numbers were written on small pieces of paper, then these papers will be mixed thoroughly after which the participants for this study will be selected.

STAGE 4: Proportionate sampling will be used to determine the number of students from each of the selected schools that will participate in the study

The following formula will be used:

$\mathrm{X}=$

Where;

$\mathrm{X}=$ number of female students to participate in the study

$\mathrm{n} 1=$ number of female students in each school

$\mathrm{n} !=$ sample size

$\mathrm{N}=$ population size.

Table 3 showing the Proportionate sample size distribution of study participants in each of the selected schools

\begin{tabular}{|l|l|l|c|}
\hline Serial Number & Town & School & Number of participants \\
\hline 1 & Iperu & Ajagbe Community Grammar school & 102 \\
\hline 2 & Ogere & Ogere Community Grammar School & 40 \\
\hline 3 & Ikenne & Ikenne Community High School & 161 \\
\hline 4 & Ilisan & Isanbi Comprehensive High School & 71 \\
\hline 5 & Irolu & Irolu Community High School & 48 \\
\hline Total & & & $\mathbf{4 2 2}$ \\
\hline
\end{tabular}




\section{Data Collection}

The instrument used for data collection was a respondent, administered a semi-structured questionnaire. This questionnaire was structured putting into consideration the variables of this research, which are demographic, knowledge, Cognitive factors and social factors of menarche in school girls. The questionnaire will be split into various sections as described below

Section A:- Sociodemographic characteristics: This consisted of items question that shall be self-constructed about the demographic characteristics (age, gender, sex, level of parents' education, tribe and religion of the family.

Section B: Preparedness for Menarche: This consisted of questions developed by the researcher to measure the level of preparedness of menarche among in-school girls. The respondents will be asked to respond to a two-point scale ranging from Yes and No

Section C: Attitudinal Disposition Towards Menarche: This section examined the inschool girls' attitude towards menarche. This was in the form of four (4) Likert scale formats (strongly-agree, agree, strongly disagree, disagree).

Section D: Coping Mechanisms Towards Menarche: This section contained information concerning the coping mechanisms of in-school girls towards menarche. The respondents will be asked to respond to a four-point scale ranging from Always to Never.

\section{Data Collection Procedure}

The data gathering procedure involved the use of trained research assistants. Respondents were informed not to put their names on the questionnaire to ensure anonymity. A letter of consent was presented to the respondents to sign before administering the survey instrument. The purpose and contents of the questionnaire were explained to the respondents stating the fact their identity would not be disclosed.

\section{DATA ANALYSIS AND DATA MANAGEMENT}

A coding guide was developed to facilitate data entry. Each questionnaire was coded and entered into a computer-facilitated by a developed coding guide. The data were analyzed using statistical software package SPSS 27.0 version. Frequency distribution table and summaries of descriptive statistics, inferential statistics were used and the data were summarized using charts and tables.

\section{Validity and Reliability of the Instrument}

1. Face Validity: the researcher consulted the supervisor in the development of the instrument to ensure that the structure, the nature of item response patterns are adequate and appropriate, and also to ensure that the different sections of the instrument were well arranged. 
2. Construct Validity: the researcher with the supervision and guidance of the supervisor ensured that sections of the instrument reflect the variables to be examined as well as the objectives of the study.

3. Instrument Reliability: the reliability of the research instrument was tested through a pilot study where it was administered to $10 \%$ of the study population and a reliability test was carried out with the responses received.

Table 4: Table showing the Cronbach Alpha to determine the reliability of the instrument

\begin{tabular}{|l|c|c|l|}
\hline VARIABLE & $\begin{array}{l}\text { CRONBACH } \\
\text { ALPHA }\end{array}$ & $\begin{array}{l}\text { NUMBER } \\
\text { OF ITEM }\end{array}$ & REMARK \\
\hline Preparedness For Menarche & .816 & 15 & Reliable \\
\hline Attitudinal Disposition Towards Menarche & .879 & 8 & Reliable \\
\hline Coping Mechanisms Towards Menarche & .881 & 9 & Reliable \\
\hline
\end{tabular}

\section{Ethical Consideration}

Ethical clearance was gotten from the Babcock University Health Research Ethics Committee (BUHREC).

\section{Informed Consent}

Consent was obtained for participants in the study. Participants were informed of the purpose of the study and the critical importance of their participation. They also reserved the right to either accept or decline participation in the study.

Confidentiality: This study was conducted in a manner that assured health information confidentiality. The data was collected and entered on a password-protected personal computer to restrict access to confidential information.

Anonymity: The data was also de-identified to ensure that a third party couldn't match participant information with health records at the study site.

Right to Withdraw: During the conduct of this study, study participants were informed of their right to withdraw from participation at any point whatsoever. 
African Journal of Health, Nursing and Midwifery

ISSN: 2689-9418

Volume 4, Issue 4, 2021 (pp. 31-51)

www.abjournals.org

\section{RESULTS}

Table 5 Analysis of Characteristics of the Student

Demographic Characteristics

Frequency Percentage

Age

5-10years

289

68.5

10-15years

90

21.3

16-20years

43

10.2

Mean Age $=11.5 \pm$ S.D $=2.63$

Age at Menarche

8years

59

14.0

9years

70

16.6

11years

112

26.5

12years

55

13.0

13years

57

13.5

14years

69

16.4

Mean Age at Menarche $=11.2 \pm S . D=2.00$

\section{Religion}

Christianity

Islam

155

36.7

Others (traditional and atheist)

9.0

Ethnicity

Yoruba

Igbo

104

24.6

Hausa

1

.2 
African Journal of Health, Nursing and Midwifery

ISSN: 2689-9418

Volume 4, Issue 4, 2021 (pp. 31-51)

\section{Place of Residence}

Urban Area

146

34.6

Sub-urban

187

44.3

Rural

89

21.1

\section{Father's level of education}

No formal education

Primary education

101

23.9

Secondary education

264

62.6

\section{Mother's level of education}

No formal education

Primary education

Secondary education

Tertiary education

\section{Father's occupation}

Government employee

Private organisation employee

$113 \quad 26.8$

Self-employed cooperate

Self-employed trader

Self-Employed hawker

\section{Mother's occupation}

Government employee

Private organisation employee

Self-employed cooperate

Self-employed hawker 
Table 4.1.1 presented below indicated that the majority $298(68.5 \%)$ of the girls were between the ages of 5-10years, some, $90(21.3 \%)$ were between the ages of 10-15years while only $10.2 \%$ of the respondents were between the ages of $16-20$ years. Their mean age is 11.5 2.63 .

Most of the students (112) experienced menarche at the age of 11, making up 26.6\%, the next common age at menarche was 9 as indicated by 70 of the respondents experiencing it at that age constituting $16.6 \%$, some (59) had their first period at the age of 89 the lowest for the group of respondents) making about $14 \%$ of the population, $13.5 \%$ of the respondents (55) recorded their age at menarche to be $13,13 \%$ of the respondents (57) experienced menarche at the age of 12 while the oldest age at menarche for this group of respondents was 14 years and this was experienced by $16.4 \%$ of the population (69).

The most practised religion among the respondents was Christianity as more than average of the respondents, $(54.3 \%)$ were Christians, followed by Islamic religion as evidenced by $36.7 \%$ of the respondents that were Muslim, and only 9\% were from other religious affiliation. The majority of the respondents were predominantly from the Yoruba ethnic group, making up $75.1 \%$ of the population, $24.6 \%$ were from the Igbo ethnic group, while only a few, $0.2 \%$, were from the Hausa ethnic group.

Most of the girls (187) reported residing in a suburban environment, 146 of them $(34.6 \%)$ reported residing in an urban area while $21.1 \%$ (89) reside in a rural environment. Most of the respondents' fathers $(62.6 \%)$ had the basic level of education (secondary education), $23.9 \%$ had only primary education, and $13.5 \%$ had no formal education. Among the mothers, the majority of the respondents (32\%) reported that their mothers had secondary education, $28.9 \%$ of the respondents' mothers had primary education while $24.2 \%$ of the respondents stated that their mothers had no formal education and $14.9 \%$ of the respondents' mothers had tertiary level of education.

The majority of the girls(120), 28.4\%, reported that their fathers were government employees, $26.8 \%$ of the respondents' fathers worked in private companies, $24.4 \%$ of the respondents reported that their fathers were self-employed cooperate, $27.5 \%$ of the respondents claimed that their fathers were self-employed trader and only $2.8 \%$ of the respondents reported that their fathers were self-employed hawker. Among the mothers, a large portion of the respondents, $25.8 \%$ reported that their mothers were self-employed cooperate; a significant portion $22.3 \%$ stated that their mothers were self-employed trader, also, an ample portion, $21.8 \%$ of the respondents reported that their mothers were selfemployed hawkers, then, $20.9 \%$ of the respondents stated that their mothers were private organisation employees, while, a few of the respondents $9.2 \%$ were government employees.

\section{Level of Preparedness for menarche among In-School girls}

Table 6 presented below most of the respondents, $66.1 \%$ have heard about menarche, 33.9\% have not heard about menarche. Magazines seem to be the major source of information for the girls with $43.8 \%$ of the respondents (185) attributing it as their source of information, this is closely followed by newspapers as supported by $33.4 \%$ of the respondents (141), while $22.7 \%$ (96) knew about it through books.

Most of the girls, $66.6 \%$ of the population had heard about menstruation, only $33.4 \%$ of the respondents claim to not have heard about menstruation. The main source of information 
about menstruation was attributed to mothers as indicated by $32.9 \%$ of the respondents' population, the next major sources of information were sisters to the respondents as reported by $28.4 \%$ of the respondents' population, while $27.7 \%$ of the respondents reported schools and books bring up the rear with only $10.9 \%$ of the respondents attributing it to as a source of information.

The preponderance of the respondents, $82.7 \%$, claimed to be aware of menstruation before the onset of menarche, with only $17.3 \%$ reporting not being aware of menstruation before the onset of menarche. A large number of the respondents, 353 comprising $83.6 \%$ knew what a sanitary towel was before the onset of menstruation, with a few, $16.4 \%$ of the respondents reported not knowing what a sanitary towel was. An ample number of the respondents, $82.7 \%$, knew how to use a sanitary towel before menarche, while respondents that reported not knowing the usage before menarche made up $17.3 \%$ of the population of the respondents. More than the average number of the respondents, $66.8 \%$ reported having heard about proper hygiene practice to adopt before starting menstruation, with some of the respondents, $33.2 \%$ reporting not being told about the proper hygiene practices. A copious percentage, $66.8 \%$ of the girls reported to have absorbent when they started menstruating, while the remaining $33.2 \%$ did not have an absorbent. $67.3 \%$ reported not feel well prepared when they started menstruating. More than half of the girls knew what to do then, $49.5 \%$ did not know what to do. $49.5 \%$ told someone while $50.5 \%$ reported to have not informed anyone when they started menstruating. 39.1\% of the respondents reported having discussed with their sister, $14.5 \%$ discussed with their father, $17.1 \%$ discussed with their mother, $29.4 \%$ discussed with their friend. Most of the girls were in a place of worship when the menstruation started, $31.3 \%$ were in school, $18.5 \%$ were at home, and $15.4 \%$ were with their friends.

Table5 level of preparedness for menarche among in-school girls $\mathrm{N}=\mathbf{4 2 2}$

\begin{tabular}{|c|c|c|c|}
\hline Preparedness for Menarche & Categories & Frequency & Percentage \\
\hline \multirow[t]{2}{*}{ Have you heard of "Menarche" before } & Yes & 279 & 66.1 \\
\hline & No & 143 & 33.9 \\
\hline \multirow[t]{3}{*}{ Where did you hear about menarche } & Newspaper & 141 & 33.4 \\
\hline & Magazine & 185 & 43.8 \\
\hline & Books & 96 & 22.7 \\
\hline \multirow[t]{2}{*}{ Have you heard of menstruation } & Yes & 281 & 66.6 \\
\hline & No & 141 & 33.4 \\
\hline \multirow[t]{4}{*}{ Sources of information } & Sister & 120 & 28.4 \\
\hline & Mother & 139 & 32.9 \\
\hline & Book & 46 & 10.9 \\
\hline & School & 117 & 27.7 \\
\hline Were you aware of menstruation before & Yes & 349 & 82.7 \\
\hline the onset of menarche & No & 73 & 17.3 \\
\hline Did you know what a sanitary towel was & Yes & 142 & 33.6 \\
\hline before the onset of menarche & No & 280 & 66.4 \\
\hline Did you know how to use a sanitary towel & Yes & 349 & 82.7 \\
\hline before menstruation & No & 73 & 17.3 \\
\hline Were you told about the proper hygiene & Yes & 282 & 66.8 \\
\hline practices to adopt before you started & No & 140 & 33.2 \\
\hline
\end{tabular}




\section{menstruation}

\begin{tabular}{|c|c|c|c|}
\hline \multirow{2}{*}{$\begin{array}{l}\text { Did you have an absorbent to use when you } \\
\text { started menstruation }\end{array}$} & Yes & 282 & 66.8 \\
\hline & No & 140 & 33.2 \\
\hline \multirow{2}{*}{$\begin{array}{l}\text { Did you feel prepared when you started } \\
\text { menstruating (menarche }\end{array}$} & Yes & 138 & 32.7 \\
\hline & No & 284 & 67.3 \\
\hline \multirow{2}{*}{$\begin{array}{l}\text { Did you know what to do at the time of } \\
\text { menarche }\end{array}$} & Yes & 213 & 50.5 \\
\hline & No & 209 & 49.5 \\
\hline \multirow{2}{*}{$\begin{array}{l}\text { Did you tell anyone when you stated } \\
\text { menstruating }\end{array}$} & Yes & 209 & 49.5 \\
\hline & No & 213 & 50.5 \\
\hline \multirow[t]{4}{*}{ Who did you discuss with } & Mothers & 72 & 17.1 \\
\hline & Father & 61 & 14.5 \\
\hline & sister & 165 & 39.1 \\
\hline & Friend & 124 & 29.4 \\
\hline \multirow[t]{5}{*}{ Where were you at the time of menarche } & Home & 78 & 18.5 \\
\hline & School & 132 & 31.3 \\
\hline & Place & 134 & 31.8 \\
\hline & Worship & 65 & 15.4 \\
\hline & Others & 13 & 3.1 \\
\hline
\end{tabular}

Table 4.1.6: Summary of level of preparedness for menarche among in-school girls $\mathrm{N}=\mathbf{4 2 2}$

Criteria Frequency Percentage

\begin{tabular}{ccc}
\hline High (19-28) & 171 & 40.5 \\
Average (10-18) & 143 & 33.9 \\
Low(1-9) & 108 & 25.6 \\
Mean =24.6, Std. Dev $=\mathbf{2 . 0 8}$ \\
\hline
\end{tabular}

This study asked 15 questions relating to the level of preparedness for menarche among the in-school girls in Ikenne Local Government Area. The maximum score obtainable is 28. Their preparedness is categorized as High (19-28), Fair (10-18) and low (1-9). 40.5\% of the in-school girls have a high level of preparedness, $33.9 \%$ had an average level of preparedness while $25.6 \%$ had a low level of preparedness for menarche.

\section{Attitudinal Disposition towards menarche among In-School girls}

Table 7 presented below indicated that $35.5 \%$ of the girls disagreed that they felt dirty when they started menstruation. $37.7 \%$ of the respondents strongly disagreed that they felt more grown-up when they started menstruating. $33.9 \%$ of the respondents strongly agreed that they feel ashamed at the time of menarche. Also, 38.9\% of the girls feel proud to have started menstruating. $37.2 \%$ of the girls strongly agreed that it was annoying as at the time of menarche. $34.1 \%$ of the respondents reported that they felt being punished as the time of 
African Journal of Health, Nursing and Midwifery

ISSN: 2689-9418

Volume 4, Issue 4, 2021 (pp. 31-51)

www.abjournals.org

menarche. $32.9 \%$ of the respondents disagreed to have felt excited to have started menarche. $36 \%$ of the respondents felt neutral about starting menstruation.

Table 7 Attitudinal Disposition towards menarche among In-school girls $\mathrm{N}=\mathbf{4 2 2}$

\begin{tabular}{|c|c|c|c|c|}
\hline $\begin{array}{l}\text { Attitudinal Disposition } \\
\text { towards menarche }\end{array}$ & $\begin{array}{l}\text { Strongly } \\
\text { Agree }\end{array}$ & Agree & Disagree & $\begin{array}{l}\text { Strongly } \\
\text { Disagree }\end{array}$ \\
\hline $\begin{array}{l}\text { I felt dirty when I started } \\
\text { menstruation }\end{array}$ & $120(28.4 \%)$ & $63(14.9 \%)$ & $89(21.1 \%)$ & $150(35.5 \%)$ \\
\hline $\begin{array}{l}\text { I felt more grown up when I } \\
\text { started menstruating }\end{array}$ & $159(37.7 \%)$ & $81(19.2 \%)$ & $120(28.4 \%)$ & $62(14.7 \%)$ \\
\hline $\begin{array}{l}\text { I was ashamed at the time of } \\
\text { menarche }\end{array}$ & $143(33.9 \%)$ & $134(31.8 \%)$ & $60(14.2 \%)$ & $85(20.1 \%)$ \\
\hline $\begin{array}{l}\text { I was proud to start } \\
\text { menstruating }\end{array}$ & $164(38.9 \%)$ & $115(27.3 \%)$ & $82(19.4 \%)$ & $61(14.5 \%)$ \\
\hline $\begin{array}{l}\text { I was annoyed at the time of } \\
\text { menarche }\end{array}$ & $157(37.2 \%)$ & $130(30.8 \%)$ & $45(10.7 \%)$ & $90(21.3 \%)$ \\
\hline $\begin{array}{l}\text { I felt I was being punished at } \\
\text { the time of menarche }\end{array}$ & $144(34.1 \%)$ & $81(19.2 \%)$ & $59(14 \%)$ & $138(32.7 \%)$ \\
\hline $\begin{array}{l}\text { I was excited at the time of } \\
\text { menarche }\end{array}$ & $107(25.4 \%)$ & $130(30.8 \%)$ & $139(32.9 \%)$ & $46(10.9 \%)$ \\
\hline $\begin{array}{l}\text { I felt neutral about starting } \\
\text { menstruation }\end{array}$ & $152(36 \%)$ & $140(33.2 \%)$ & $118(28 \%)$ & $12(2.8 \%)$ \\
\hline
\end{tabular}

Table 7: Summary of level of attitudinal disposition towards menarche among in-school girls $\mathrm{N}=422$

\begin{tabular}{ccc}
\hline Criteria & Frequency & Percentage \\
\hline Positive (17-32) & 208 & 49.4 \\
Negative (1-16) & 214 & 50.6 \\
Mean $=\mathbf{1 6 . 1}$ Std. Dev $=\mathbf{2 . 8 8}$ \\
\hline
\end{tabular}


This study asked 8 questions relating to the level of attitudinal disposition towards menarche among the in-school girls in Ikenne Local Government Area. Maximum score obtainable is 32. Their level of attitudinal disposition is categorized as Positive (17-32), and Negative (116). Majority of the in-school girls $50.4 \%$ had a negative level of attitudinal disposition towards menarche, $49.6 \%$ had positive levels of attitudinal disposition towards menarche.

\section{Test of Hypothesis}

\section{Hypothesis One}

$\mathbf{H}_{\mathbf{0}}$ : There is no significant relationship between the level of preparedness for menarche and the attitudinal disposition of in-school girls in Ikenne Local Government

$\mathbf{H}_{1}$ : There is a significant relationship between the level of preparedness for menarche and the attitudinal disposition of in-school girls in Ikenne Local Government

The outcome of the first hypothesis stated that "there was a significant relationship between the level of preparedness for menarche and the attitudinal disposition of in-school girls in Ikenne Local Government " the null hypothesis rejected. Table 8 revealed a significant relationship between the level of preparedness for menarche and the attitudinal disposition of in-school girls in Ikenne Local Government $(r=0.881, p<.001)$. The result shows that there was a significant relationship between the level of preparedness for menarche and the attitudinal disposition of in-school girls in Ikenne Local Government.

Table 4.2.1: Correlation between level of preparedness for menarche and the attitudinal disposition of in-school girls in Ikenne Local Government Area

\begin{tabular}{lcccr}
\hline $\begin{array}{l}\text { Preparedness } \\
\text { Menarche }\end{array}$ & for & $\begin{array}{c}\text { Attitudinal Disposition towards } \\
\text { Menarche }\end{array}$ & Total & $\begin{array}{c}\text { R } \\
\text { p-value }\end{array}$ \\
& Positive & Negative & & \\
\hline High & 88 & 83 & 171 & 0.881 \\
& $42.3 \%$ & $38.8 \%$ & $40.5 \%$ & $0.001^{* *}$ \\
Average & 68 & 75 & 143 & \\
& $32.7 \%$ & $35.0 \%$ & $33.9 \%$ & \\
Low & 52 & 56 & 108 & \\
& $25.0 \%$ & $26.2 \%$ & $25.6 \%$ & \\
\hline
\end{tabular}




\section{Hypothesis Three}

$\mathbf{H}_{\mathbf{0}}$ : There is no significant predictor of preparedness for menarche and attitudinal disposition on coping mechanism of in-school girls in Ikenne Local Government

$\mathbf{H}_{3}$ : There is a significant predictor of preparedness for menarche and attitudinal disposition on coping mechanism of in-school girls in Ikenne Local Government

The table (4.2.3) shows the regression square and p-value. Employing a 0.05 criterion of statistical significance, none of the variables had significant effects with the constant. The calculated R Squared and p-value for preparedness for menarche and attitudinal disposition is: 0.716 which signifies $71.6 \%$ contribution to coping with menarche among in-school girls in Ikenne Local Government Are. The S.E for both preparedness for menarche and attitudinal disposition are 0.074 and 0.053 respectively. Hence, both preparedness for menarche and attitudinal disposition was a significant predictor of coping mechanism of inschool girls in Ikenne Local Government Area.

Table 4.2.3: Regression showing preparedness for menarche and attitudinal disposition on coping mechanism of in-school girls in Ikenne Local Government

\begin{tabular}{|c|c|c|c|c|c|}
\hline & \multicolumn{4}{|c|}{ Coping with Menarche } & \multirow{3}{*}{$\begin{array}{c}\text { R- } \\
\text { square }\end{array}$} \\
\hline & \multicolumn{2}{|c|}{$\begin{array}{l}\text { Unstandardized } \\
\text { Coefficients }\end{array}$} & \multirow{2}{*}{$\begin{array}{c}\begin{array}{c}\text { Standardized } \\
\text { Coefficients }\end{array} \\
\text { Beta }\end{array}$} & \multirow[t]{2}{*}{ Sig. } & \\
\hline & B & Std. Error & & & \\
\hline (Constant) & 1.813 & 1.891 & & .001 & \multirow{3}{*}{0.881} \\
\hline $\begin{array}{l}\text { Preparedness for } \\
\text { Menarche }\end{array}$ & .410 & .074 & .245 & .000 & \\
\hline $\begin{array}{l}\text { Attitudinal Disposition } \\
\text { towards Menarche }\end{array}$ & .429 & .053 & .355 & .000 & \\
\hline
\end{tabular}

\section{DISCUSSION OF FINDINGS}

\section{Level of Preparedness of Menarche among in-school girls in Ikenne LGA}

The result of research question one showed that $40.5 \%$ of the in-school girls have a high level of preparedness of menarche among the girls, 33.9\% had an average level of preparedness while $25.6 \%$ had a low level of preparedness for menarche. The result of the analysis is consistent with that of Ademikanra, (2017) that most adolescent girls have a high level of preparedness for menarche in Nigeria. Timing of menarche is important to women's health in general because it has been related to the fertility and mortality rate of women in a country; specifically, menarche occurs later in countries with high mortality and fertility rates. The result on the level of preparedness is supported with the finding of Sarma, (2015) that there 
significant high level of preparedness because it is always a thing of joy for the participants. The result is also corroborated with the findings of Devi \& Ramiah, (2014) that there is a high level of preparedness of menarche among adolescent girls residing in low and middleincome countries where resources are low but it comes with lots of celebration to appreciate the joy of womanhood.

\section{Attitudinal Disposition towards Menarche}

The result of research question two showed that the majority of the in-school girls $34.4 \%$ had a moderate level of attitudinal disposition towards menarche, $33.6 \%$ had a good level of attitudinal disposition towards menarche while $32 \%$ had a poor attitudinal disposition towards menarche. The result is corroborated with the findings of Creoles and Maroons, (2016) that there is a positive disposition towards menarche among adolescent girls residing in Uganda. The result is also similar to Ten, (2017) in that it is believed that menstrual blood pollutes the home and such customs still exist in some Asian and African cultures. Furthermore, EI-Gilanya, Badawib \& AL-Fedawyb (2015) opined that in Egypt there is a belief about bathing during menstruation is to be avoided totally. The study further reported that although proper menstrual hygiene requires access to water and sanitation facilities, myths and cultural misconceptions block access to these facilities rendering the intended users unable to use them, thereby resulting in the risk of the girls' hygienic needs being compromised. Additionally, Adebami \& Sarumi, (2015) revealed that very few girls use unsanitary absorbent materials and that high cost or non-availability of absorbents materials were not exactly not an issue. Although, this was found to be attributable to the high socioeconomic status of the respondents' mothers in terms of employment.

Hypothesis one: The result of hypothesis one showed that there was a significant relationship between the level of preparedness for menarche and the coping mechanism of inschool girls in Ikenne Local Government. The result corroborates with the findings of Devi \& Ramiah, (2014) that there was a significant association between level of preparedness and coping with menarche among adolescent in-school students in rural communities of Ogun State. The result corroborates with the findings of Creoles and Maroons, (2016) shows an even higher degree of exclusion than others, this was further explained that menstruating women are not just excluded from domestic activities but are taken far away from their community to the far end of the village or confined to a separate room in the house. Furthermore, the result is in tandem with the findings of Allison \& Hyde, (2013) that timing of menarche has a profound impact on the preparedness for menarche through social and emotional adjustments on the girls, and the age at which it occurs differ among women of different cultures.

Hypothesis two: The result of hypothesis two indicated that the calculated R Squared and pvalue for preparedness for menarche and attitudinal disposition is: 0.716 which signifies 71.6\% contribution to coping with menarche among in-school girls in Ikenne Local Government Area. The result is consistent with findings that teenage girls often obtain information about menstruation from their mother, school, friends, and advertisements of sanitary products (Koff \& Rierdan, 2015). Furthermore, Menke, (2018) reported that good preparation for menarche and the disposition of individuals towards menarche is a strong motivation for coping with the experience of menarche among in-school adolescent girls. Additionally, Tracy, Grover, \& Macgibbon, (2016) that South-West Nigeria, some girls, especially those from low socioeconomic backgrounds, considered sexual activity to be their 
means of socioeconomic survival hence, their level of preparedness and attitudinal disposition is very low. Furthermore, Shakweer, (2016) that misconceptions about the physiological processes and characteristics of menarche are evident among girls preparing for menarche. mothers who have information about reproductive health and menarche often withhold such information to prevent their girls from becoming "promiscuous (Forward, 2016).

\section{CONCLUSION AND RECOMMENDATION}

Adolescence in girls signifies the transition from girlhood to womanhood. Good menstrual hygiene is crucial for the health, education, and dignity of girls and women. This is an important sanitation issue which has long been in the closet and still there is a long standing need to openly discuss it. The menarche represents a landmark event in pubertal development of the adolescent girl. Menarche, and the menstrual cycle are characterized by variability in volume, pattern and regularity, which at the earlier stages of the development of the adolescent can create emotional discomfort particularly to the poorly informed girl. The study established that: Most of the students $40.5 \%$ of the in-school girls have a high level of preparedness for menarche. Majority of the in-school girls $34.4 \%$ had moderate levels of attitudinal disposition towards menarche. Majority of the in-school girls $45 \%$ had a good level of coping mechanism towards menarche among in-school girls. There was a significant relationship between the level of preparedness for menarche and the attitudinal disposition of in-school girls in Ikenne Local Government. There was a significant relationship between the level of preparedness for menarche and the coping mechanism of in-school girls in Ikenne Local Government. The calculated R Squared and p-value for preparedness for menarche and attitudinal disposition is: 0.716 which signifies $71.6 \%$ contribution to coping with menarche among in-school girls in Ikenne Local Government Area. Based on the outcomes of this study, it is hereby recommended that:

1. There is a need for teachers to build a peaceful and healthy transition into womanhood through adequate preparation and provision of resources for young girls.

2. Parents should create more time towards for their female adolescents towards given necessary psychosocial support as they enter menarche

3. The school should create health week to enable student ventilate their mind towards menstruation and menstrual cycle

4. The school should partner with Non-governmental organisations towards provision of good menstrual hygiene and provision of menstrual kits for young female adolescents in secondary schools. 


\section{REFERENCES}

Adebimpe, R.A (2017) Young women"s attitudes toward continuous use of oral contraceptives: The effect of priming positive attitudes toward menstruation on women"s willingness to suppress menstruation. Health Care for Women International, 29(7), 688-701. doi:10.1080/07399330802188925

Ademikanra, I.O (2016) The social science of the management of menarche. Nigerian Journal of Social Science. 22(5), 90-122

Ajao, Y.O (2019) Beliefs about menstruation: A study from rural Pondicherry. Indian Journal of Medical Specialities, 2(1), 23-26. doi:10.7713/ijms.2011.0006

Aluko, J (2018) Menstruation: Symptoms, management and attitudes in university students. International Journal of Gynecology and Obstetrics, 35, 147-150. doi:10.1016/00207292/91/90818-P

Awolude, Y.O (2018) Beliefs about menstruation: A study from rural Pondicherry. Indian Journal of Medical Specialities, 2(1), 23-26. doi:10.7713/ijms.2011.0006

Bartky, J.O (2017) Leptin in reproduction. Current Opinion in Endocrinology, Diabetes and Obesity, 458-464.

Chrisler, A.O., (2016) Expectations about menstruation among premenarcheal girls. Medical Anthropology Newsletter, 8(4), 16-25

Deardorff J, G. N. (2017). Early puberty and adolescent pregnancy: the influence of alcohol use. Pediatrics, 1451-1456.

Forward, O.O (2016) Menstrual Hygiene among Adolescent School Girls in Mansoura Egypt.Reproductive Health Matters. 13: 193-154

Golub, F., (2016) Experiences and attitudes related to menstruation among female students. Pakistan Journal of Psychological Research, 27(2), 201-224. Retrieved from http://www.pjprnip.edu.pk/pjpr/index.php/pjpr/article/viewFile/195/171

Ibaishwa, R. L. \& Achakpa, P. M. (2016). Menstrual hygiene management amongst marginalized physically challenged women and adolescent girls in 10 states of Nigeria. Women Environmental Programme. 1-60

Jegede, R.O (2019) Social Construction of Menstration among the Yoruba in Nigeria. Journal of Ethnographic Medicine. 2,(12-33

Kamath, A.F., Ghosh, I.O., Lena, A.S., \& Chandrasekaran, R.O (2016) Age of menarche in females with autism spectrum conditions. Developmental Medicine and Child Neurology, 1007-1008.

Koff, K.L \& Rierdan, S (2015) Adolescent girls define menstruation: A multiethnic exploratory study. Health Care for Women International, 31, 831-847. doi:10.1080/07399331003653782

Koff, L.O., \& Rierdan, Y.O (2015) Attitudes and feelings towards menstruation and womanhood in girls at menarche.Acta Pediatricta,707-714

Lyth, I.O., Simmons, R.O., \& Zakin, U.A (2015) Risk factor for anorexia nervosa: Three integrated case-control comparisons. Archives of General Psychiatry, 56, 468-476

Marván, M. L., \& Alcála-Herrera, V. (2016). Age at menarche and attitudes towards menstruation among Mexican adolescent girls. Journal of Pediatric and Adolescent Gynecology,61-66

Omigbodun, O.O Bella-Awusah, T.O \& Adeniyi, C.Y (2018) Attitudes and feelings towards menstruation and womanhood in girls at menarche. Acta Paediatrica, 95(6), 707-714. doi: 10.1080/08035250500531697 
Patle, Y.A., \& Kubde, A.A (2019) Women's reproductive factors and incident cardiovascular disease in the UK Biobank. Heart., 1069-1075.

Shanbhag, D (2016). erceptions regarding menstruation and practices during menstrual cycles among high school going adolescent girls in resource limited settings around Bangalore city, Karnataka, India. Int J Collaborative Res Intern Med Public Health.

Singh, J (2016) Understanding depression: Feminist social constructionist approaches. London: Routledge

Singh, S., Darroch, J., \& Ashford, L. (2014). Adding it up: the costs and benefits of investing in sexual and reproductive health. New York: Guttmacher Instituite

Tiwari, N, (2016) Age at menarche in two caste groups (Brahmins \& Rajputs) from rural areas of Jammu. Anthropologist, 8(1), 55-57.

United Nations Children's Fund, (2018) \#EndAdolescentAIDS. Joint United Nations Programme on HIV/AIDS. Geneva: UNIADS

Walvoord, H. (2011) Cultural practices relating to menarche and menstruation among adolescent girls in Taiwan - qualitative investigation. Journal of Pediatric and Adolescent Gynecology, 25(1), 43-47. doi: 10.1016/j.jpag.2011.08.006 